\title{
KAJKAVSKI SVJETOGLED BOŽICE JELUŠIĆ
}

\author{
Pjesništvo kao ingeniozno sjećanje \\ Wer Sprache hat, "hat" die Welt ${ }^{1}$ \\ Hans-Georg Gadamer \\ Marijan Varjačić, Varaždin
}

\section{Sažetak}

U pjesništvu Božice Jelušić estetske vrijednosti neodvojive su od *ethosa; njeno pjevanje upravo je jezik ethosa.

Fran Galović, Ivan Golub i Božica Jelušič pjesnički su trolist bitno određen jezikom i zavičajem. Njihovo pjesništvo, međutim, nije zavičajno samo u isključivo sadržajnom nego i u smislu temeljnog iskustva svijeta. Lirika prirode Božice Jelušić bitno je ekološka, u izvornom značenju grčke riječi ${ }^{\star}$ oikos = kuća/dom; čovjek je u prirodi pri sebi samom.

Ključne riječi: zavičaj i ethos zavičaja; jezik i svjetogled (Weltansichten); zavičajna književnost; pamćenje i sjećanje

Moji, s majčine strane, starinom su Virovci (Plemenčići). Baka je odišla $v$ zamuž u nedaleke Srednje Mosti, već brežuljkasti predio u blizini bilogorskih šuma. Djed i baka po ocu doselili su u podravsko-bilogorski kraj poslije Prvoga rata iz srca Zagorja. U ranom djetinjstvu živio sam u Pitomači i Mostima, gdje sam rođen, kršten i primio prvu pričest. Materinji jezik mi je dakako kajkavski. Odgojem sam pak Varaždinec; firma u župnoj crkvi sv. Nikole, gimnazijski vjeronauk kod Kapucina, vjeroučitelj fra Bono Zvonimir Šagi. Za rane, deteče dobe, za

${ }^{1}$ Tko ima jezik, “ima” Svijet, u: Hans-Georg Gadamer, Wahrheit und Methode. Grundzüge einer philosophischen Hermeneutik, J. C. B. Mohr (Paul Siebeck), Tübingen, 1990., str. 457. i d. 
primer, spominam se: bijelih noći kad se kretala povorka na polnoćku, sprijeda stariji s lampašima, po prtini iza njih djeca; mirisa dunja s ormara u velkoj hiži gdje je ležao djed Matija s lijepo zafrkanim mustačima, dok su žene poluglasno molile; bakine starinske škrinje pod ključem u maloj hiži; oskoruša kaj se mekšaju na tavanu u žitu ...

S Božicom Jelušić dijelim slične u s p o m e n e koje su odredile naš život; to je moje polazište za razumijevanje i njezinog pjesništva. Razumijevanje uvijek pretpostavlja neko "predrazumijevanje" (Ververständnis), ono je uvjetovano i osobnom poviješću koja proizlazi iz podrijetla i životne povijesnosti (Lebensgeschichte) pojedinca. ${ }^{2}$

Reiner Maria Rilke 1925. godine u pismu Witoldu Hulewiezu piše o "sve bržem nestajanju mnogočega vidljivog, što se više ne će obnoviti”. Za naše djedove i bake "kuća", "zdenac", "vanjkušek" ili "ćup" npr., bili su nešto "beskrajno više, beskrajno prisnije". "Sad", piše Rilke, "preko Amerike nadiru prazne stvari, patvorine, atrape života ... Kakva bilo kuća, po američkom shvaćanju, američka jabuka i tamošnji čokot nema ničega zajedničkog s kućom, plodom, grozdom, u koji se upila nada i sjena naših praočeva”. Mnoge su stvari potrošene i ne mogu se nadomjestiti. Na onima koji su takve stvari poznavali, kaže Rilke, odgovornost je da ne samo sačuvaju uspomenu na njih već i njihovu humanu i larsku vrijednost. Takve vrijednosti sačuvane su u pjesništvu Božice Jelušić. O "larskim vrijednostima" ona progovara i u svom "kajogledu" Od Cintora do cybera. ${ }^{3}$

\section{O ČUPIMA, dva-tri slova}

Tam smo išli k staroj hiži,

Gdi na steni vise križi.

Čez gančec, nuz staru klupu,

Mamilo nas mleko v čupu!

Spiju kokoši na prečki.

V komoricu, poskrivečki,

Zamotani z mekom kmicom,

Skorupa obirat z žlicom.

Dišalo je po vrčaku,

Po štaglju i kolinjaku,

\footnotetext{
${ }^{2}$ Isto, str. 272. i d. Hermeneutičko predrazumijevanje, prema Gadameru, nije predrasuda.

${ }^{3}$ Božica Jelušić, Od cintora do cybera, Kajkavsko spravišče, Zagreb, 2004., str. 39-44.
} 
Ploske, flaše, graj vu vreči.

Blago čuva čup bleščeči.

Skorup, putro ili stepke,

Za sakiden $i$ za svetke.

Za žgance i bazlamače,

Za zlevanke i prkače.

Živeli smo tu bez greha:

Krumpir z rola, kostanj z pleha!

Tam gdi maček brke suče,

Stalo vreme negibuče!

Vre ganjčeca veter mete.

Rastrga kaj pavuk splete.

$V$ čupu kmica i čkomina,

V prah je otišla starina!

Ruho pojeli su moljci,

$V$ svet su prešli samovoljci.

Kotač v blatu gda zariži,

Idu ljudi, idu križi ...

(ploska - rakijska bočica, flaša; stepki - sirutka; negibuči - nepomičan; prkači - domaći kolačići; zarižati - zapeti kolskim kotačem u blatu)

U stvarima, jednako kao i u jeziku, sačuvan je duh naših praočeva. Kao i jezik, stvari govore. Nestajanjem tih stvari umire jedan svijet. Ključna riječ u odnosu prema stvarima o kojima pjeva Jelušićka je povjerenje, pouzdanost. Upravo to gubimo u odnosu prema "praznim stvarima" koje "nadiru" brojem i brzinom nezamislivima u ne tako davno doba o kojem govori Rilke. To je tema kojom se bavio i jedan od najutjecajnijih mislilaca 20. stoljeća Martin Heidegger. Tek u povjerljivosti, pouzdanosti (Verläßlichkeit) uviđamo što stvar/oruđe uistinu jest. ${ }^{4}$ Podašna je stvar, kaže Heidegger, vrč i klupa, brv i ralo. Ali stvar je, na svoj način, i drvo i ribnjak, potok i brijeg, kao čaplja i srna, kao što su na svoj način knjiga i slika, kruna i križ. U predavanju Das Ding (Stvar) koje je Heidegger održao u Bavarskoj akademiji lijepih umjetnosti 1950., odgovarajući na pitanje

\footnotetext{
${ }^{4}$ Martin Heidegger, Der Ursprung des Kunstwerkes, Klostermann, Frankfurt am Main,
} 2012., str. 20. 
što je stvar po sebi, kao primjer za raščlambu uzeo je zemljani vrč koji je izradio lončar; već na početku pokazuje se da vrč, kao uopće stvar, "nipošto nije puki predmet". Sličan odnos kao prema stvarima u užem smislu Jelušićka gaji prema prirodi. Njena je lirika sva uistinu ekološka, u izvornom značenju grčke riječi oikos = kuća/dom; čovjek je u prirodi pri sebi samome.

U pjesništvu Božice Jelušić estetske su vrijednosti neodvojive od ethosa; njeno pjevanje upravo je jezik ethosa. Tome ne proturječi, naprotiv, "povratak artizmu" o kojem pjesnikinja piše kao o svojoj "osobnoj poziciji”. Za Platona ljepota stvari i ljudi nije nešto s druge strane dobra. U pozadini toga stoji opće grčko shvaćanje o jedinstvu lijepog i dobrog ${ }^{5}$; za to su Grci iskovali riječ kalokagatia (kalos kai agathos, lijep i dobar). U dijalogu Hipija Veći postavlja se pitanje da li je ljepša posuda od zlata ili od maslinova drva (u našem slučaju: zemljana posuda). Za Sokrata je stvar jasna. Posuda od zlata može doduše sjati, ali ona je nepraktična, nespretna za rukovanje i ne slaže se (ne harmonizira) s ukusom kaše koju u njoj treba miješati. Dakle posuda od maslinova drva je ljepša i to se pokazuje kako u njenoj upotrebi tako i u ukusu kaše. Bolja posuda je ljepša posuda; bolji čovjek je ljepši čovjek. Ideja o jedinstvu lijepoga i dobroga ponovno oživljava od 18. stoljeća. Za Kanta, unatoč razlici lijepog i dobrog, "lijepo je simbol ćudoredno dobroga" ("das Schöne ist das Symbol der Sittlichkeit”, §59 Kritik der Urteilskraft). Za Schillera je pak to dokaz njihove bitne podudarnosti. I u suvremenim raspravama govori se o umjetnosti kao "mediju etičke refleksije", tj. sredstvu ćudorednog propitivanja. Teza o estetskoj autonomiji pak podrazumijeva estetski uspjelu, ali amoralnu/nećudorednu umjetnost.

\author{
SENCA NA PODRAVSKEMI PUTI \\ Miroslavu Dolencu - Dravskomu \\ Čez šume crlene, čez fajtne baršune, \\ gdi guščerska koža se lešči zvrh mulja \\ za hitrom sencom zlatne kune, \\ dok dravski Te pesek v cipeli žulja ... \\ Čez senokoše, ponjave prestrte, \\ $z$ belem konjičecom našlingane; \\ dok joči več vrtaju luknje vu vrte, \\ kak škrinje starinske, rasključane.
}

\footnotetext{
${ }^{5}$ I danas se vode rasprave o odnosu etike i estetike. V. npr. C.H. Menke, Sauveränität der Kunst, 1991. O tome piše i T. S. Eliot u svojim esejima (v. npr. Tradicija, vrijednosti i književna kritika, Matica hrvatska, Zagreb, 1999., str. 60 i d.)
} 
I dalje: $v$ gustiš, tam gdi se glasa

štiglec, kos, šojka - pisanorepka.

Dole, do sela, gdi još se belasa

megla kak gusta, zgruđvana šterka.

A ona skriva kaljavo dvorišče;

koce i koše, s kukuruzom pune.

I ruka se pruža i v plastu išče

jabuku, lepšu od carske krune.

I ruka pušča v zdenec vedricu,

a voda spere prašinu $z$ nepca.

Onda se v štalu nalukneš, a kmicu

ražari jognjeno joko ždrepca.

Počinka nema ... Ve dalje je iti, po belom putu do rastika.

Tu žiri šepču pod listjem skriti, i breni brenčeča jelenska rika.

Pak onda: čez koprive i trputec, do groblja gdi stoje klimavi križi.

Vekvečen Putnik i trdogutec,

si došel k sebi, $k$ svojoj hiži?

Se mi se vidi da još si od puta.

Gle, tam Te čeka vrba kuštrava!

I čez šaš plazi lena, rastegnuta

debela kača ... Tvoja DRAVA. Drava!

Vre šepčéš spašen, šepčeš joj ves blažen:

"Z Tebom bi mogel nakraj sveta stiči!"

Cel den tak sediš. Digneš se osnažen

kajti te znova na put zovu ftiči ...

Čez šume crlene, čez fajtne baršune,

gdi guščerska koža se lešči zvrh mulja;

za hitrom sencom zlatne kune,

dok dravski Te pesek v cipeli žulja ...

10./1995. 
(fajtno - vlažno; ponjava - plahta; našlingan - raščipkan; šterka - štirka; vedrica - vjedro; breni - brenči, odjekuje)

Fran Galović, Ivan Golub i Božica Jelušić pjesnički su trolist bitno određen jezikom i zavičajem. U nas se rabio pojam "regionalna književnost" s pomalo nepoćudnim prizvukom. Zavičajno pjesništvo odnosno književnost (njem. Heimatdichtung, Heimatliteratur) je tematski određen natpojam (hiperonim) za svako književno stvaranje iz doživljaja zavičaja, određenog krajolika i njegovih ljudi, kao i života u seoskoj zajednici, ne samo u isključivo sadržajnom nego i u smislu temeljnog iskustva svijeta. Zavičajna književnost u najobuhvatnijem pojmu je prema tome u temelju svake književnosti, pa tako i "velegradske".

Zavičaj je rječnički: 1. mjesto rođenja, 2. rodni kraj. Za + prasl. vyknoti: naviknuti se = zavičajnost. Navika je i u korijenu grčke riječi ethos (uobičajeno mjesto života, običaj, navada). Ethos kao lat. mos (običaj, navika) i njem. Sitte (norma, običaj, navada) po smislu su gotovo istoznačne riječi. I u hrvatskom jeziku zavičaj se dakle povezuje s etičkim, moralnim odnosno ćudorednim. Izvorno pitanje o zavičaju pripada etici (philosophia moralis) i u tom smislu možemo govoriti o etosu zavičaja. Riječ domovina rječnički je također "mjesto gdje se tko rodio" ili zavičaj. Izvedenica je od riječi dom, koja je i dobrim dijelom objašnjava. Vladimir Mažuranić bilježi: dom, m., domus, u značenju kuća, stan, domovina, zavičaj, baština, pleme, koljeno, hiža, svojta, bratstvo, krv i dr.

Nitko nije o zavičaju govorio uzvišeno kao Platon. Nakon smrti besmrtni dio duše vraća se tamo gdje joj je korijenje; čovjek "nije zemaljsko nego nebesko bilje" i zato se uzdiže "sa zemlje svom nebeskom srodstvu" (Timej 90a), gdje ima doticaja s božanskim, besmrtnim i neprolaznim bićem (Fedar 250e-253c). Čovjekova se duša vraća u svoju duhovnu domovinu ili zavičaj. Pavao u Drugoj poslanici Korinćanima $(5,1)$ kaže:'Dakako, znamo: ako se ovaj šator, naša zemaljska kuća, ruši, imamo zgradu koja je djelo Boga, vječna kuća na nebesima, koja nije sagrađena ljudskom rukom". Prema Heideggeru, zavičaj je "blizina bitka", a bezavičajnost "počiva u napuštenosti bića od bitka". Bitak u smislu Heideggerovom i Bog suvremene teologije, pri svojoj različitosti, vrlo su bliski.

S Ivanom Golubom vraćamo se na Zemlju. Svoj kajkavski spjev Kalnovečki razgovori završio je stihovima:

F knigi piše da je Bog čoveka od zemle napravil.

$\mathrm{Je}$, ali od one zemle na kojoj se čovek rodi. 
Bog je čovjeka načinio od zemlje (Post, 2,7). ${ }^{6}$ Adam, znači čovjek a riječ je istog korijena kao âdâmâh, što znači zemlja. Doslovni prijevod riječi Adam/ čovjek glasio bi zemljar ili pozemljar... To je polazište Golubova teološko-poetskog kazivanja o zavičaju. U semitskom svijetu ime ne znači samo razlučivanje nego i određivanje onoga koji ga nosi. Adam/čovjek/zemljar iskazuje da je zemlja bitna za čovjeka. Slikovito govoreći, možemo kazati da je svaki čovjek stvoren od zemlje, i to od one zemlje na kojoj se rodi; svaki je čovjek Adam/zemljar. Rodna zemlja je sastavnica čovjekova bića. "Što više živim", piše Golub, "to više vidim kako svatko nosi u sebi zemlju na kojoj je rođen, od koje je stvoren: sve što je njome označeno, mentalitet zavičaja, značajke kraja, srodnost s onima koji su napravljeni od iste zemlje".

Zavičajem se bavi i suvremena filozofija. Za Karen Joisten čovjek je zavičajno biće (hematlilches Wesen), a zavičaj je temeljni, ako ne čak i središnji problem filozofije. Filozofija se može shvatiti kao mišljenje zavičaja (Denken von Heimat) jer su u njenom središtu pitanja odakle i kamo, o mjestu čovjekova življenja, njegova sazrijevanja i suočavanja sa sobom. ${ }^{7}$ Prema hrvatskom filozofu Zlatku Posavcu, i umjetnost i umjetnik imaju zavičaj. Osobnost umjetnika bez zavičaja bila bi egzistencijalno ispražnjena općenitost, fraza, jedva čak i ono Heideggerovo das Man. I danas valja podsjetiti na Senekinu opomenu: Nusquam est qui ubique est!/Nigdje nije (onaj) tko je svugdje! ${ }^{8}$

Vrhunac, u kojem su sjedinjeni zavičajnost, jezik i duhovnost, Božića Jelušić ostvarila je u zbirci pjesama Jezuši. Ivan Golub piše: “Jezik zbirke je zavičajan. To mu daje povlašćenost iskona. Zavičajan se jezik pokazuje kao majka, pramajka. Posve u smislu one Heideggerove: Dijalekt je jezik majke, ali i majka jezika". U eseju Zavičaj i jezik Hans-Georg Gadamera čitamo:"Zavičaj je, da upotrijebim znamenitu Schellingovu riječ, nešto što je od pamtivijeka (etwas Unvordenkliches). Što bi zavičaj odnosno domovina bila da nema jezika. To je nešto od pamtivijeka zahvaljujući ponajviše jeziku. Materinski jezik sadrži nešto od pretpotopne ili iskonske zavičajnosti". ${ }^{9}$

Fran Galović je za pjesme koje će ispjevati pred smrt ( $Z$ mojih bregov) "izabrao" materinski kajkavski, a o zavičaju/domaji, zapravo o bezavičajnosti, ispjevao je dvije antologijske pjesme: Childe Harold na standardu i Kostanj na kajkavskom.

${ }^{6}$ Prikaz prema: Ivan Golub, Dar dana šestog, u: Golub, Sabrana blizina, Mozaik knjiga, edicija Biseri hrvatske književnosti, Zagreb, 2003., str. 488-492.

${ }^{7}$ Karen Joisten, Philosophie der Heimat - Heimat der Philosophie, Akademie, Berlin, 2003.

${ }^{8}$ Zlatko Posavec, Hrvatska estetika i povijesno mišljenje, Filozofska istraživanja br. 45, Zagreb, 1992., str. 325.

${ }^{9}$ Hans-Georg Gadamer, Heimat und Sprache, u: Gadamer, Ästhetik und Poetik, I, Kunst und Aussage, J. C. B. Mohr Paul Siebeck, Tübingen, 1993., str. 366-372. 
Sve iskustvo i spoznaja su jezikoliki. I danas je živa misao Wilhelma von Humboldta da je sve značenje značenje određenog jezika i da on određuje naše "osvajanje" svijeta, našu sliku svijeta odnosno svjetogled (Weltansichten). Jezik je izvanjska pojava duha naroda (Geistes der Völker); "njegov jezik njegov je duh i njegov duh je njegov jezik, nikada se oboje ne može misliti dovoljno istovjetno" (ihre Sprache ist ihr Geist und ihr Geist ihre Sprache, man kann sich beide nie indentisch genug denken). ${ }^{10}$

Jelušićkin kajkavski je "spoj različitih tradicija: osnova je habdelićevskomulihovska, pridodan je temeljni vokabular srednjepodravskih govora, a otprilike trećina je izmišljena, pri čemu se nastoji ne iznevjeriti korijen ili barem temeljni slog". ${ }^{11}$ To je "svojevrsni metajezik". ${ }^{12}$ Njen jezični sustav nije samo jezična, već i estetska tvorevina.

\section{PREGNANCI MOLE JEZUŠA}

Pomogni nam, Jezuš, ostani z nami.

$V$ megli kak testo zgubil se svet.

Mi pregnanci smo, trpeči, sami.

Na križoputju Ti visiš raspet.

Se je krvavo, zežgano, strto.

Našu su muku skljuvale čavke.

Gdi kucaš, najdeš joko zastrto:

vu njem su pozoji, kače, pijavke.

Ornice hrđaju pod jabukom.

Obgoren tram se vu kalu črni.

Kruv naš se preobrnul v kamen.

Ti nas posveti Svojom mukom.

V ponjavu snega se nas zagrni.

Vmrti nam daj na našem. Amen.

\footnotetext{
${ }^{10}$ Franz-Michael Konrad, Wilhelm von Humboldt, UTB Profile, Göttingen, 2010., str. 96.

${ }^{11}$ Božica Jelušić, Može li pijetao biti orao, u: Jelušić, Od Cintora do cybera, Kajkavsko spravišče, Zagreb, 2004., ste. 28-32.

${ }^{12}$ Isto
} 
(pregnanci - prognanici; pozoj - zmaj, ala, drakun; kača - zmija; ponjava - plahta; križoputje - raskrižje)

Ivan Golub piše: "Izgnati čovjeka iz rodnog mjesta gotovo je jednako ubojstvu ... izgon iz rodnog mjesta je postupak protivan rađanju - dakle umiranje. Čovjeka se može ubiti na dva načina: nasilnim trganjem niti života (koja ima svoj početak u rodnom mjestu) ili izgonom iz rodnog mjesta. Zašto prognanici žele u opustošeno rodno mjesto? ... Zacijelo zato što ih vuče zemlja iz koje su sazdani, što im život tu ima svoj početak, svoj razvitak". ${ }^{13}$

\section{MOLITVA JEZUŠU ZA LEHKU SMRT}

Spasi me, Jezuš, smrti boleče, od štrika, noža, kugle žareče;

zlosilne smrti i zločinjenja, okrutne smrti bez zlahkotenja.

Spasi me, Jezuš, od beteguvanja, skečanja, javkanja i skoznuvanja: postelje zimlične, betežničke, gumbekov z škatulje, kapljic z flašičke.

Prosim Te, daj mi smrt hitru, lehku; pod starem dudom il' na poceku, gdi lepše se vmira nek v zemlji stranjski.

Si moji vmirali su na vrtu, vu dvoru.

Zmed dve-tri reči vu razgovoru, si moji vmirali su človečanski ...

(zlahkotenje - olakšanje; beteguvanje - boležljivost, bolovanje; skoznuvanje - bdjenje; zimlično - grozničavo; pocek - prag)

Pjesma Molitva Jezušu za lehku smrt govori o človečanskom umiranju: smrt pod starem dudom, na poceku, na vrtu, vu dvoru, zmed dve-tri reči vu razgovoru, na našem, u krilu d o m a, kao i u Kalnovečkim razgovorima Ivana Goluba.

${ }^{13}$ Ivan Golub, Dar dana šestog, u: Golub, Sabrana blizina, Mozaik knjiga, edicija Biseri hrvatske književnosti, Zagreb, 2003., str. 490. 
Ethos zavičaja jedna je od poveznica pjesnikinje Jelušić i duhovnika, teologa i pjesnika Goluba. Za njega pak zajednica nije samo zajednica čovjeka sa čovjekom nego i čovjeka s Bogom. ${ }^{14}$

\section{VETER}

Zločesti je veter granje skumpesal,

Čerepe zesipal, steklovje potrl.

Železnem česalom se nas je sčesal,

kervavu robaču v ledinu otrl.

Brat hudodušni, nigdar ni vustal.

Bokčiju našu rastepal po polju.

Žvalavom labrnjom kosti je hrustal,

kotural lubanje po podolju.

Kak oroslan je v cintoru rúčal,

bobental v zvone, zibal zvonike.

Med črnemi cipresi na groblju hučal:

vun 'zemlje zval nas, mrtve mrtvike.

(skumpesati - raščupati; čerepi - crijepovi; česalo - željezna četka za marvu; hudodušni - zlodušni, demonski; vustati - umoriti se; labrnja - životinjska vilica; oroslan - lav; cintor crkvište; cipresi - čempresi; mrtviki - mrtvaci)

Pjesma Veter iz ciklusa Hrvatski triptih A.D. 1993. izuzetna je po načinu tematiziranja zla (pridružuju joj se i pjesme Pozoj, Tri krali, Nočna steza, Tanec...). Osobita je također po "gomilanju" glagola i mahom glagolskim rimama. Po tome nije usamljena; glagoli su možda ključne riječi u Jelušićkinoj lirici. Humboldt je držao da se u glagolu najjasnije i najjače izriče osobitost jezika: "Sve ostale riječi su tako reći mrtva zatečena građa koju treba povezati glagol, glagol je jedina središnja točka što sadrži i zrači život. Misao, ako se smije tako slikovito kazati, napušta putem glagola svoje nutarnje prebivalište istupajući prijeko, u zbilju". U dramama Tituša Brezovačkog Ivo Hergešić nabrojio je čak 23 izraza za jedan jedini pojam, tj. glagole "tuči” i "istuči”. U Rječniku varaždinskog kajkavskog govora Tomislava Lipljina za "vudriti” postoji 57 istoznačnica!

${ }^{14}$ Marijan Varjačić, Kalnovečki svet. Uz 85-letnicu Ivana Goluba, Kolo, 3/2015., Zagreb, str. 163-171. 
Osim "gomilanja" glagola u Božice Jelušić često se javlja nizanje pridjeva i priloga. Te osobitosti u kajkavskom pjesmotvorenju povezuju je s Miroslavom Krležom, točnije, u temelju povezuje ih jezik sam.

Muze su kćeri Zeusa i boginje Mnemosine, ${ }^{15}$ među njima je i Erato, muza lirike, naročito ljubavnog pjesništva, sa žičanim glazbalom u rukama. Muze su bile božanske zaštitnice i rapsoda, za čiju umjetnost je nuždno umijeće pamćenja. U Božice Jelušić pamćenje, sjećanje i uspomene, kao i u Rilkea, imaju dublji smisao od pukog predočavanja onoga što bijaše i suprotstavljanja sadašnjosti ili od pasatističke nostalgije, kao u nekih pjesnika hrvatske moderne (npr. Domjanić i Vojnović) ${ }^{16}$. Kao u Platonovoj anamnesis (prisjećanje), u njenom pjesničkom prisjećanju zbiva se istinska spoznaja. Pjesničke se spoznaje temelje na prisjećanju odnosno uspomeni, pa je i put/let pjesnikove duše nalik onome u Platonovom Fedru (245d-249d). Sjećanje je bit pjesništva; pjesništvo je bitno sjećanje.

Metafizički pojam sjećanja (grč. anamnesis, lat. recordatio, njem. Erinnerung) u filozofskoj predaji svojstven je racionalizmu: od Platona preko Augustina, R. Descartesa, G.W. Leibnitza, G. W. F. Hegela i F. J. Schellinga, S. Kierkegaarda, do E. Husserla i M. Heideggera. Na različit način određuje se kao predznanje općenitoga koje dolazi do izražaja u "ponovnoj spoznaji" posebnoga. Objašnjava se, npr., učenjem o urođenim idejama (Descartes), razvitkom duha u sjećanju (Hegel) koncepcijom sjećanja das Ich "transcendentalne prošlosti" (Schelling, filozofija prirode). Na Schellinga nadovezuje se psihoanaliza Freuda. Romantizam razumije sjećanje kao objedinjavajuću snagu mašte. Otuda F. Schlegel i Novalis poistovjećuju sjećanje s poezijom. Romantičari pokušavaju povratiti Mnemosinu kao ponovno uvođenje jedne kulturno obvezujuće, mitske slike svijeta. I. Kant razlikuje (Antropologija, \$31) mehaničku, judicioznu (prosuđivačku) i ingenioznu (izumjelačku) memoriju. ${ }^{17}$ Prva proizlazi iz doslovnog ponavljanja jedne za drugom predodžbi, ne uzimajući u obzir sadržaj. Druga uzima u obzir povezanost/srodnost predodžbi, njihov logički i stvaran odnos, njihov raspored i siste-

${ }^{15}$ Mneio, e, mneme, mnemosine, epski i mnestis, tos, e, ep., jon., i poet., sjećanje, uspomena, spomen, spominjanje, pamćenje, pamet, slovo.

${ }^{16}$ V. Zoran Kravar, Prošlošću (i s prošlošću) protiv civilizacijske moderne, u: Batušić/Kravar/ Žmegač, Književni protusvjetovi, Matica hrvatska, Zagreb, MMI, str. 197 i d.

${ }^{17}$ Lat. memoria, ae, pamet, 1. moć sjećanja, 2. spomen, uspomena; memini, sjećati se, spominjati se čega, pamtiti što; ingenium, 1. prirođena ćud, narav, svojstvo, 2. o čeljadi: a) po moralnosti: ćud, narav, temperament, značaj, b) po razboritosti, po talentu: govornički dar, oštroumlje, dosjetljivost, fantazija. 
matsko ustrojstvo. Treća, ingeniozna memorija povezuje pojedinačno na umjet nički način, asocijativno prema sličnosti i razlici, i simbolički preko "izmišljanja” znakova. Prema Kantu, ingenium je urođena sposobnost kojom priroda daje pravila umjetnosti (die Natur durch das Genie ... der Kunst die Regel vorschreibe, $\$ 46$ Kritik der Urteilskraft). Za modernu je svojstveno da sjećanje ne provodi kao svjesno dozivanje u svijest, nego prije svega kroz nezamijećene detalje (usp. Proustovo mémoire ivolontaire = nehotimično sjećanje, protiv vlastite volje). Sjećanje je jedan od postupaka postmoderne umjetnosti...

Rasprava o urođenim idejama (lat. ideae innatae) i urođenom znanju koja se vodi danas nastavlja se na raspravu između R. Descartesa (naše su ideje urođene, npr. pojam Boga) i J. Locka (sve ideje izvedene su iz iskustva). Određeni stupanj urođenosti u umu danas zastupaju gotovo svi; suvremena rasprava vodi se zapravo oko pitanja što je i koliko urođeno, je li urođen samo opći mehanizam ili je urođen i sadržaj znanja. Prema suvremenoj filozofiji jezika, postoje jezična načela koja nisu naučena, “jezične univerzalije” u umu. U tom smislu N. Chomsky govori o "platonizmu bez pretpostojanja”; urođeni su "principi univerzalne gramatike”. Chomsky je svoje zamisli razvio na tragu R. Descartesa i W. von Humboldta. ${ }^{18}$ Naša pjesnikinja, pišući o Miroslavu Dolencu-Dravskom, kaže: "Znao je ono što je važno i koliko je čovjek lišen sjećanja, ustvari ispražnjen od duhovne suštine". Sasvim u dosluhu s Augustinom u desetoj knjizi Ispovijesti ...

Deseta knjiga Augustinovih Confessiones/Ispovijesti, o pamćenju i sjećanju, pripada vrhuncima filozofske psihologije, nauka o duši. ${ }^{19} \mathrm{Na}$ početku $(\mathrm{X}, 8,12)$ Augustin kaže: et venio in campus et lata praetoria memoriae, ubi sunt thesauri innumerabilium, imaginum de cuisque modi rebus/i evo dolazim na poljane velike dvorane pamćenja, gdje je zaliha/riznica nebrojenih slika svakojakih stvari. U pamćenju nisu samo slike stvari: ono čuva prijašnja čuvstva $(\mathrm{X}, 14,21)$, u njemu je znanje o istini $(X, 23,33)$ i pojmovi samih stvari koje nismo primili ni kroz jedna vrata $(X, 14,22)$. "Velika je snaga pamćenja, nešto strašno, Bože moj, neka duboka i beskrajna mnogostrukost! I to je moja duša, to sam ja sâm ... Evo u mom pamćenju bezbrojnih polja, špilja i zakutaka, puno bezbroj rodova nebrojenih stvari, bilo po slikama, kao kod svih tjelesa, bilo po prisutnosti, kao kod umjetnosti, bilo po nekim pojmovima ili oznakama, kao kod duševnih čuvstava ... Po svemu tome beskraju trčim ja i prelijećem ovamo i onamo, prodirem također naprijed, koliko mogu, i nigdje kraja! Tolika je snaga pamćenja, tolika životna snaga u čovjeku koji živi smrtnim životom!” (X, 17, 26). O sjećanju Augustin

${ }^{18}$ V. članak Dunje Jutronić, Urođene ideje u suvremenom ruhu, Filozofska istraživanja br. 70, Zagreb, 1998., str. 655-667

${ }^{19}$ Ispovijesti su ujedno jedno od najslavnijih djela svjetske literature. 
kaže: Ego sum, qui memini, ego animus/Ja sam onaj koji se sjeća, ja duša (X, 16, 25). ${ }^{20}$ Augustin povezuje platonski nauk o anamnesis sa svojom spoznajom sadržaja i biti pamćenja, odnosno sjećanja.

Pjesništvo Božice Jelušić je i entuzijastičko. Grč. enthusiasmos znači božansko oduševljenje, zanos, ushićenje (lat. in-spirare, u-disati, nadahnuti). To je stanje u kojem čovjek u potpunosti izlazi izvan sebe (grč. ekstenai) i biva ispunjen Bogom, koji preko njega govori i djeluje. Grčki pjesnici smatrali su da su samo slušači, dok je ta koja pjeva Muza sama. Zazivanje Muza na početku djela (npr. prvi stihovi Ilijade i Odiseje) pripada od najstarijih vremena tradiciji grčkog pjesništva. Kad je Zeus dovršio preoblikovanje svijeta, upitao je bogove nedostaje li što za savršenost. Oni su odgovorili da nedostaje samo božanski gla s, kako bi se očitovala i slavila ta veličanstvenost, te su ga molili da porodi Muze ... Novoplatoničar Sallustius odredio je mit kao ONO ŠTO SE NIJE NIKADA DOGODILO, ALI JEST UVIJEK. "Ali tko se bez nadahnuća Muza približi vratima poezije, misleći da će moći svojim umijećem (tehnes) postati valjan pjesnik taj ostaje neposvećen, i njegovu poeziju kao stvar razuma pomračuje poezija onoga koji pjeva u zanosu" (Platon, Fedar 245a). ${ }^{21} \mathrm{O}$ ushitu/božanskom zanosu govori i Aristotel (Politika, 1342a, 5-15). U biblijskoj inspiraciji imamo prijelaz od neposrednog nadahnuća prema posrednom ili spisateljskoj inspiraciji. Kant i Hegel govore o uzvišenom duševnom stanju/raspoloženju; na taj način počinje psihologiziranje poetske mašte. ${ }^{22}$

Grč. idein, lat. vedere, znači gledati nešto što se već vidjelo, te tako imati spoznaju o nekoj stvari i biti upućen u ophođenje s njom. Ili: u sjećanju sada vidimo ono trajno, bitno koje nam je bilo skriveno. Božica Jelušić je pjesnikinja VIDJELICA, pjesnikinja koja VIDI istinu. ${ }^{23}$

${ }^{20}$ V. Augustinus, Confessiones-Bekenntnisse, Lateinisch/Deutsch, Reclam, Stuttgart, 2018., str. 461-564., Aurelije Augustin, Ispovijesti, Kršćanska sadašnjost, Zagreb, 1999., str. 214-237.

${ }^{21}$ Malo slobodnijim tumačenjem Platona, slično o umijeću kazuju stihovi pjesme Božice Jelušić Lauda parafinska iz zbirke Kotačev slavopoj (2018.): "Metafore što su, tropi, sinonimi, / ako ti u leđa strast ne daje vjetar?". To ne umanjuje značaj umijeća ili kako bi Božica rekla artizma. Strast ukazuje na neku pokrenutost u visinu, što upravo nosi hrvatska riječ strast, mnogo više nego npr. njemačka Leidenschaft. Strast možemo shvatiti kao analogon entuzijastičkom zanosu.

${ }^{22}$ Emmanuel Kant ( $\$ 29$ Kritik der Urteilskraft) govori o “estetičkom entuzijazmu” kao "napinjanju snaga" (Anspanunng der Krafte), "koje duši daje polet" (welche dem Gemüte einen Schwung geben).

23 "Umjetnost je spoznaja posebne vrste, drukčija od svake moralne, umske i pojmovne spoznaje, ali ipak spoznaja, što znači posredovanje istine" (Hans-Georg Gadamer, Wahrheit und Methode. Grundzüge einer philosophischen Hermeneutik, J. C. B. Mohr (Paul Siebeck), Tübingen, 1990., str. 103.) 
THE KAJKAVIAN WORLDVIEW OF BOŽICA JELUŠIĆ

Poetry as ingenious recollections

By Marijan Varjačić, Varaždin

\section{Summary}

The aesthetic values in the poetry of Božica Jelušić are inseparable from ${ }^{*}$ ethos; her canorous poetry is, in fact, the language of ethos.

Fran Galović, Ivan Golub, and Božica Jelušić are a threesome of poets essentially defined by language and homeland. However, their poetry is not exclusively native as to content, but also in their basic sense of experiencing the world. Božica Jelušićs lyrics linked with nature are substantially ecological, in the primary meaning of the Greek word ${ }^{*}$ oikos = house/home; a human in natural environment is at home with himself.

Key words: homeland and homeland's ethos; language and worldview; homeland literature; memory and remembrance 